\title{
Effect of Thermal Processing on Shelf Stable Canned Salted Beef with Tomato Gravy
}

\author{
Ankur Singh ${ }^{1}$, T. R. Genitha ${ }^{2}$, Rongen $\operatorname{Singh}^{3}$, B. R. Shakya ${ }^{4}$ \\ ${ }^{1}$ M.Tech Student, ${ }^{2,3}$ Assistant Professor, ${ }^{4}$ Associate Professor, Department of Agricultural Process and Food \\ Engineering. \\ Allahabad Agricultural Institute- Deemed University, Allahabad-211 007 U.P. India
}

\begin{abstract}
Studies were conducted to analyze the characteristics of shelf stable canned salted beef with tomato gravy involving the effect of thermal processing. Product standardization was done by traditional method utilizing tomato gravy along with salted beef for making shelf stable canned meat. After that the optimized preservative concentration and thermal treatments were given to it at different temperature time combinations viz., $110^{\circ} \mathrm{C} 115^{\circ} \mathrm{C}$ and $121^{\circ} \mathrm{C}$ for 20,30 and 40 minutes respectively in order to interpret the effect of thermal processing and salt as a preservative. Samples were evaluated initially and after that at the intervals of 0,15 , 30, 45, 60, days for sensory analysis. Microbiological, chemical and sensory studies were conducted after each 15 day interval up to other 60 days in order to depict the increase in shelf life stability due to application of curd as an emulsifier (i.e. effect of preservative and thermal processing). It was found that the thermal processing of shelf stable canned salted beef with tomato gravy done at $121{ }^{\circ} \mathrm{C}$ for 40 minutes had significantly superior acceptability and the adequate protein, fat, moisture content was found significantly superior in $110^{\circ} \mathrm{C}$ for 40 min.
\end{abstract}

Keywords: Product Standardization, Thermal processing, Canning, Sterilization, Shelf life study.

\section{INTRODUCTION}

Indian meat industry has emerged as the most dynamic and rapidly expanding segment of livestock economy as in evident from the production level of 4.9 million tonnes with recent export of 0.27 millions tones fetching worth about Rs. 1400 crores of foreign exchange. Meat is recognized as highly nutritious food being an excellent source of high quality protein. Containing a good balance of the essential amino acids and having high biological value. (Rastogi et al.1978). Buffaloes are exported for slaughter from India and Pakistan to the Middle East and from Thailand and Australia to Hong Kong. Demand for meat is so great that Thailand's buffalo population has dropped from 7 million to 5.7 million head in the last 20 years, a period in which the human population has more than doubled. (Charles and Johnson1972).

Ready-to-eat foods have also been defined as the status of the food being ready for immediate consumption at the point of sale. It could be raw, cooked, hot or chilled and can be consumed without further processing. Ready- to-heat foods are fully cooked with long shelf life, up to 2-3 years and beyond depending upon the storage condition. Most commonly RTE foods have been defined as those foods which are ready for consumption, only to be reheated and consumed. For example Indian curries, deserts, frozen heat and eat products like chicken and mutton curry, canned beef meat etc. which are generally retorted and are shelf stable. (Mann and Breashers 2007). Unlike pasteurized "cooked" meat products where the survival of heat resistant microorganisms is accepted the aim of sterilization of meat products is the destruction of all contaminating bacteria including their spores. Heat treatment of such products must be intensive enough to inactivate/kill the most heat resistant bacterial microorganisms, which are the spores of Bacillus and Clostridium. Temperatures above $100^{\circ} \mathrm{C}$, usually ranging from $110-121^{\circ} \mathrm{C}($ Han et al.2004).

\section{Materials And Methods}

The experiment was conducted in self fabricated A $2 \frac{1}{1} 2$ size can in the laboratory at the Department of Agricultural Process \& Food Engineering, AAI-DU. Product development \& thermal Processing of ready to eat Salted Beef with Tomato Gravy was conducted in a tin can.

2.1. Materials used: Meat, vegetables, refined oil, common salt, curd, meat masala, dry spices, lemon.

\subsection{Method for the preparation of Salted Beef with Tomato Gravy}

\subsubsection{Salted Beef with Tomato Gravy Preparation}

Meat brisket (meat cut from the chest of the animal/buffalo) was washed properly with tap water; the raw meat was placed in the pan of (5 liters) capacity, cover with cold water and brings gently to the boil. After the cooking was done properly to get the soft tendering texture in the product, the surface of the beef loaf was covered with salt, lemon and sugar, and leave for several hours. Meat was turned regularly during the next six 
days salt was rubbed into the beef loaf each time and spoon the brine over the beef. Then, after six days, the beef was ready to be cooked.

\subsubsection{Preparation for the gravy}

All vegetables and spices were grinded properly onion, tomato, garlic, green chilly, salt, cloves, cumin seeds, black cardamom, green cardamom, bay leaves, black pepper corn and meat masala. The above mentioned grinded ingredients and the putted into the gently boiled refined (sunflower) oil and cook it until the required taste was developed.

\subsection{Final preparation of the Salted Beef with Tomato Gravy}

The chopped meat loaves were deeply fried in the refined oil. These fried pieces were filled into the empty cans with the prepared tomato gravy.

Product standardization

(By traditional method)

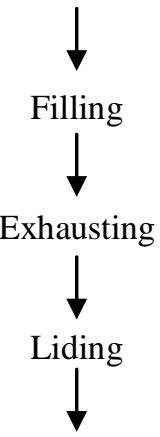

Thermal processing

(Autoclaving at $110,115 \& 121^{\circ} \mathrm{C}$ for $20,30 \& 40 \mathrm{~min}$ )

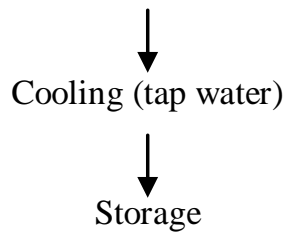

2.3.1. Process flowchart for the thermal processing of Salted Beef with Tomato Gravy in cans.

Flatten can unit

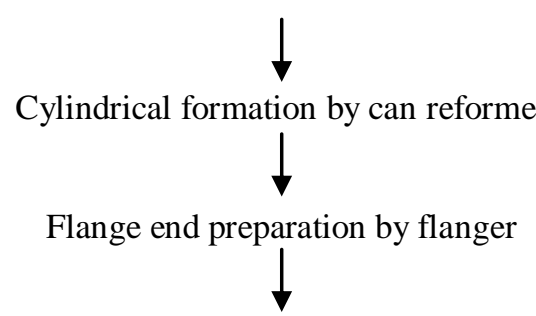

Can lid fixed with double seamer

Can examination with water

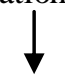

Can ready for processing

2.3.2. Can fabrication flow chart

Sterilization of can

Filling the contents in the can

Exhausting of filled can in water bath done at $80^{\circ} \mathrm{C}$ for 10 minutes 


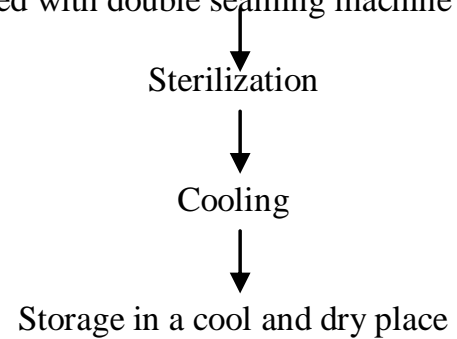

\subsubsection{Schematic flow chart for the canning process.}

\subsubsection{Microbiological analysis}

PDA and NA media was prepared and standard plate count, yeast and mould count was taken at the intervals of 15 days $(0,15,30,45$, and 60 days).

\subsubsection{Chemical analysis}

Fat, protein, moisture content, and $\mathrm{pH}$ was determined according to (A.O.A.C) method at the intervals of 15 days $(0,15,30,45,60$ days $)$.

\subsection{Product standardization}

\section{Results And Discussion}

The product standardization of salted beef with tomato gravy was done by using finishing technique, by maintaining low vacuum in the can inspite of the filling temperature and by maintaining head space (1.10) of the salted beef with tomato gravy because all the cans were filled to constant weight for maintaining the consistency of the tomato gravy depends on the emulsification. Proper filling resists the breaking of emulsion. No significant variation in the consistency was achieved, because proper emulsification was achieved by using proper composition during finishing. The product standardization was done by maintaining adequacy of thermal processing at temperatures and time treatments $\left(110^{\circ} \mathrm{C}, 115^{\circ} \mathrm{C}, 121^{\circ} \mathrm{C}\right)$ for 20,30 , and 40 minutes. The product standardization of the salted beef with tomato gravy was done by organoleptic evaluation of the product consisted of offering the curry prepared using the concentrated gravy to a panel of judges drawn from the staff indicate that there was a definite maturation and improvement during storage of salted beef with tomato gravy. The product stored at room temperature $25-30^{\circ} \mathrm{C}$ and $37^{\circ} \mathrm{C}$ and thermally processed at $121^{\circ} \mathrm{C}$ for $40 \mathrm{~min}$, up to 60 days was acceptable.

Similar results were interpreted during the acceptance of sensory, microbial, and chemical analysis of canned meat based on mutton curry and beef curry (Madhwaraj et al. 1979.)In this canned meat also sensory evaluation was carried out on 9 point hedonic scale and all analysis were conducted similarly.(Pflugg and Esselen, 1963).

The salted beef with tomato gravy was standardized by traditional recipe. The nutritional and other compositions of the product are given below:

\subsubsection{Composition}

Beef muscle $\mathrm{pH}$ (5.4), fat (3.4\%), moisture (76.6\%), protein (19\%), and ash (1\%).

Meat cuts considered for each can weighs: $250 \mathrm{~g}$

Tomato gravy with all essential ingredients for each can weighs: $250 \mathrm{~g}$

Weight of empty can : $100 \mathrm{~g}$

Weight of each packed can : $600 \mathrm{~g}$

(500 g : Salted beef with tomato gravy, $100 \mathrm{~g}$ : can weight)

\subsection{Chemical characteristics of salted beef with tomato gravy}

\subsubsection{Effect of thermal processing on protein percentage of salted beef with tomato gravy.}

\section{Protein}

Statistical analysis of protein percentage at 0 days storage was shown that the mean value at temperature TE1, i.e., 17.51 was significantly superior to the mean value at temperature TE2, i.e., 17.36 which again was significantly higher than TE3 i.e., 17.23.

Similar trend was observed by the statistical analysis of protein percentage at 0 days storage, was shored that the mean value at time T1, i.e., 17.64 was significantly superior to the mean value at time T2, i.e., 17.30 which again was significantly higher than $\mathrm{T} 3$, i.e., 17.16.

The same table shows the results during interaction analysis of protein percentage at 0 days storage was shored that the interaction at TE1+T1, i.e., 17.85 was significantly superior to the interaction at TE2+T1, i.e., 17.62 which again was significantly higher than TE3+T1, i.e., 17.45 . 
It was observed significantly by the findings of the analysis that protein was denaturated at higher temperatures during thermal processing of salted canned meat with tomato gravy and decreases the biological value of protein and physical properties of protein were affected due to high temperature and time treatments.

Protein is one which is highly digestible and absorbable and which supplies the organism with adequate amounts of the amino acids which it needs. Roasting and canning may affect the physical properties of meat protein adversely by changing the linkages so that they are not as susceptible to enzymatic digestion (Howker et al., 1976).(Morgan and Kern 1934) found that during canning of meat the biological value decreased in proportion to increase in severity of the heat treatment .

\subsubsection{Effect of thermal processing on fat percentage of salted beef with tomato gravy.}

Fat

Statistical analysis of fat percentage at 0 days storage was shored that mean the value at temperature TE2, i.e., 4.45 was significantly superior to the mean value at temperature TE1, i.e., 4.35 which again was significantly similar to TE3, i.e., 4.37 (table 4.2).

Whether at time treatments it was observed by the statistical analysis of fat percentage at 0 days storage was shown that the mean value at time T3, i.e., 4.42 was significantly superior to the mean value at time T1, i.e., 4.37 which again was significantly similar to T2, i.e., 4.39 (table 4.2).

The same table shows the results during interaction analysis of fat percentage at 0 days storage. It was observed that the interaction at TE3+T1, i.e., 4.52 was significantly superior to the interaction at TE2+T1, i.e., 4.34 which again was significantly superior to TE1+T1, i.e., 4.24 (table 4.2).

High temperature cooking of the meat in a vessel or sealed jars and cans, where the meat is roasted, sliced and sealed in jars. The layer of fat not only protects the meat from contamination but also excludes oxygen. This separation of fats results in fat embedding. As temperature increases it affects the physical properties of meat fat. (Reiser and shorland, 1990).

Similar findings were depicted during the fat estimation of canned meat (Madhwaraj et al.1979).

\subsubsection{Effect of thermal processing on $\mathrm{pH}$ of salted beef with tomato gravy. pH}

Statistical analysis of $\mathrm{pH}$ was shored that at temperature TE3, i.e., 5.59 and TE2, i.e., 5.58 was significantly superior to the mean value at temperature TE3, i.e., 5.55.

Whether at time treatments it was observed by the statistical analysis of mean value of $\mathrm{pH}$ at time $\mathrm{T} 3$ i.e., 7.67 was significantly superior to the mean value at time $\mathrm{T} 2$, i.e., 6.47 and $\mathrm{T} 1$, i.e., 6.07 .

It was shown that the results during interaction analysis of $\mathrm{pH}$ at $\mathrm{TE} 3+\mathrm{T} 3$, i.e., 5.61, TE2+T3, i.e., 5.61, and $\mathrm{TE} 1+\mathrm{T} 3$, i.e., 5.57 were insignificant.

The $\mathrm{pH}$ of meat never reaches such high acid values, but the high temperature reached during the heat treatment about 112 to $113^{\circ} \mathrm{C}$ might favor the reaction. (Morgan and Kern, 1934)), studied that during canning or roasting if the $\mathrm{pH}$ of canned meat lies between 5.4-5.8, the canned meat will be under edible conditions.

These conditions apply to foods of low acidity ( $\mathrm{pH}$ above a value of 5.5) and medium acidity ( $\mathrm{pH}-5$ ); with more acid foods the spores of micro-organisms are less heatresistant. Meat products are mostly low-acid, while meat and vegetable mixtures are medium -acid. In practice once the F-value (thermal treatment at $121^{\circ} \mathrm{C}$ ) has been determined for a batch of food according to the size of the container the heat treatment required to treat subsequent batches is the same (Bender and Zia, 1976).

\subsubsection{Effect of thermal processing on moisture percentage of salted beef with tomato gravy. Moisture content}

Statistical analysis of moisture percentage at 0 days storage was shown that mean value at temperature TE3, i.e., 73.66 was significantly superior to the mean value at temperature TE2, i.e., 73.83 which again was significantly superior to TE1, i.e., 74.02.

Whether at time treatments it was observed by the statistical analysis of moisture percentage at 0 days storage was shored that mean value at time $\mathrm{T} 3$, i.e., 73.61 was significantly superior to the mean value at time $\mathrm{T} 2$, i.e., 73.86 which again was significantly superior to T1, i.e., 74.04 .

The same table shows the results during interaction analysis of moisture percentage at 0 days storage was shown that interaction at $\mathrm{TE} 3+\mathrm{T} 3$, i.e., 73.38 was significantly superior to the interaction at TE2+T3, i.e., 73.58 which again was significantly superior to TE1+T3, i.e., 73.87 .

It was observed by the findings of the statistical analysis that moisture content of meat was decreased during canning, roasting as the temperature increases the moisture content was decreased during high thermal time and temperature treatments. High moisture content results in growth of microorganism during meat canning by using different gravy's moisture content decreases as the temperature increases. (Reiser and shorland, 1990). 

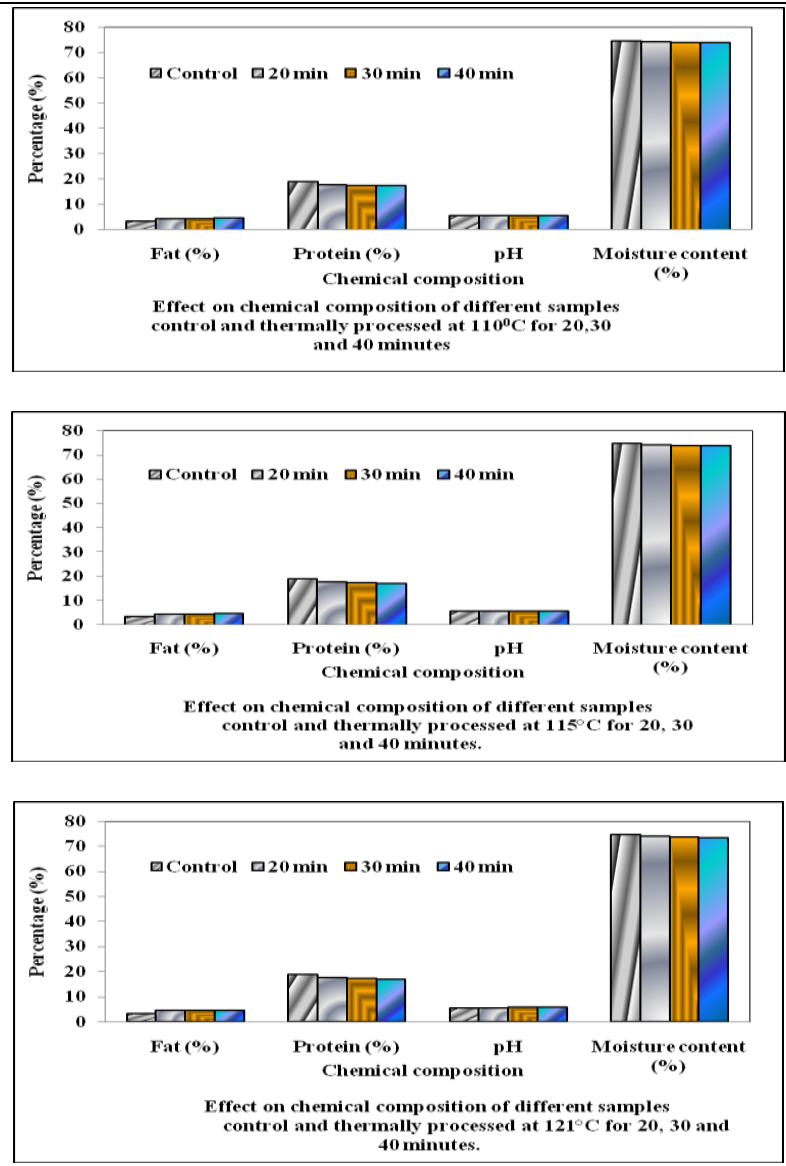

\subsection{Microbiological characteristics during storage period}

Standard plate count of canned salted beef with tomato gravy after thermal processing at $121^{\circ} \mathrm{C}$ for similar time combinations showed significant and prominent reduction in the microbial population of canned salted beef with tomato gravy. The microbial load was reduced to optimum level which clearly depicts the shelf stability of salted beef with tomato gravy. But the maximum decrease in the microbial population of the canned salted beef with tomato gravy thermally processed at $121^{\circ} \mathrm{C}$ for 40 minutes.

Statistical analysis of microbial count at 0 days storage was shown that the mean value at temperature TE3, i.e., 29.22 was significantly superior to the mean value at temperature TE2, i.e., 42.89 which again was significantly superior to TE3, i.e., 52.22 .

Whether at time treatments it was observed by the statistical analysis of microbial count at 0 days storage was shored that mean value at time $\mathrm{T} 3$, i.e., 24.78 was significantly superior to the mean value at time $\mathrm{T} 2$, i.e., 41.78 which was significantly superior to T1, i.e., 57.78 .

The same table shows the results during interaction analysis of microbial count at 0 days storage. It was shown that the interaction at $\mathrm{TE} 3+\mathrm{T} 3$, i.e., 14.33 was significantly superior to the interaction at TE2+T3, i.e., 28.00 which again was significantly superior to TE1+T3, i.e., 32.00 .

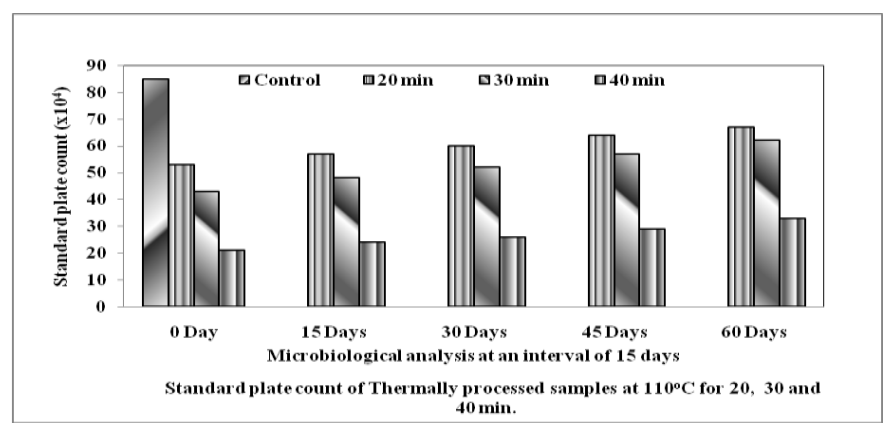



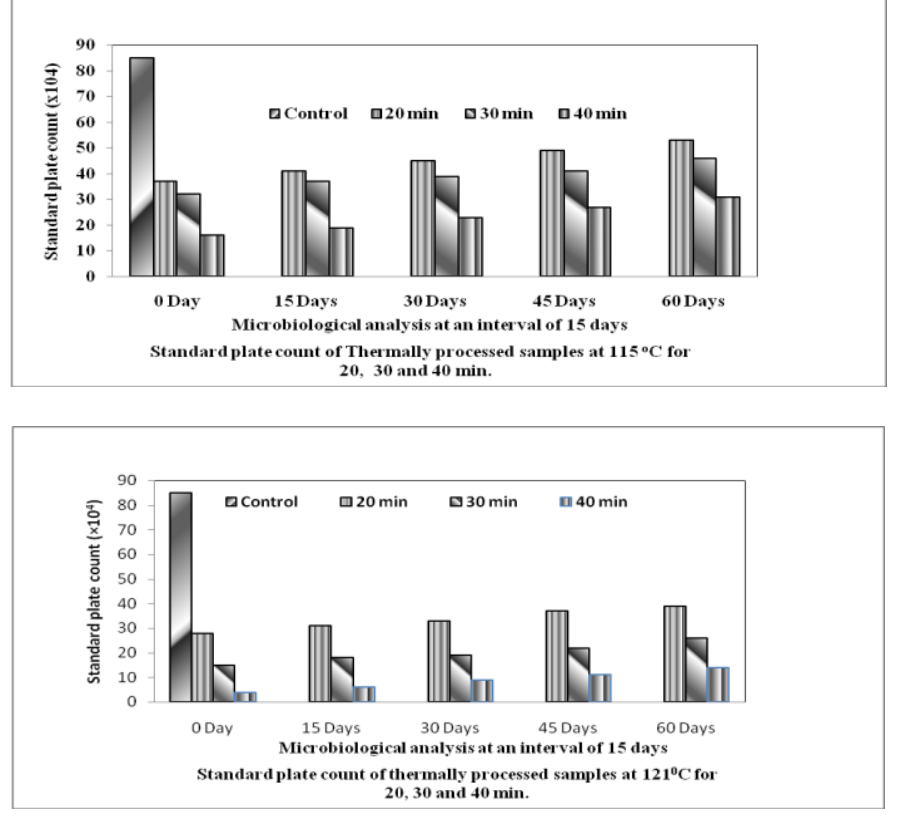

At high temperatures thermal treatments thermally processed cans of meat under gravy preparation have lowest decline at microbial load and a longer shelf life than other types of food packets such as sachets, pouches, glass jars. (Madhwaraj et al, 1979).

\subsection{Sensory characteristics}

The sensory characteristics of the canned salted beef with tomato gravy were analyzed after $0,15,30$, 45 , and 60 days were done and tabulated in table.

After comparing the mean sensory score it was found that the significant mean sensory score was observed in salted beef with tomato gravy thermally processed at $121^{\circ} \mathrm{C}$ for 40 minutes after comparing with the mean sensory score of control. Hence clearly depicts the shelf stability of the canned salted beef with tomato gravy and its maximum acceptability.

\subsubsection{Effect of different temperatures and time of thermal processing on overall acceptability characteristics of salted beef with tomato gravy.}

Same trend as above was observed in mean sensory scores of overall acceptability at temperature TE3, i.e., 6.87 was significantly superior to the mean value at temperature TE2, i.e., 6.53 which again was significantly superior to TE3, i.e., 6.40 .

Whether at time treatments it was observed by the statistical analysis of mean sensory scores of overall acceptability at time $\mathrm{T} 3$, i.e., 7.53 was significantly superior to the mean value at time $\mathrm{T} 2$, i.e., 6.60 which again was significantly superior to T1, i.e., 5.67.

The same table shows the results during interaction analysis of mean sensory scores of overall acceptability at $\mathrm{TE} 3+\mathrm{T} 3$, i.e., 8.00 was significantly superior to the interaction at TE2+T3 i.e., 7.40 which was significantly superior to TE1+T3, i.e., 7.20.

Results in consonance with the acceptability and nutritional quality of gravy based canned meat on beef curry and mutton curry (Madhwaraj et al 1979). Results are in confirmation with the the development of instant ready to eat mutton curry was organoleptically acceptable (Das and Radhakrishna 2001).

Similar results were interpreted during statistical analysis of colour, taste, aroma, flavour, sensory characteristics.

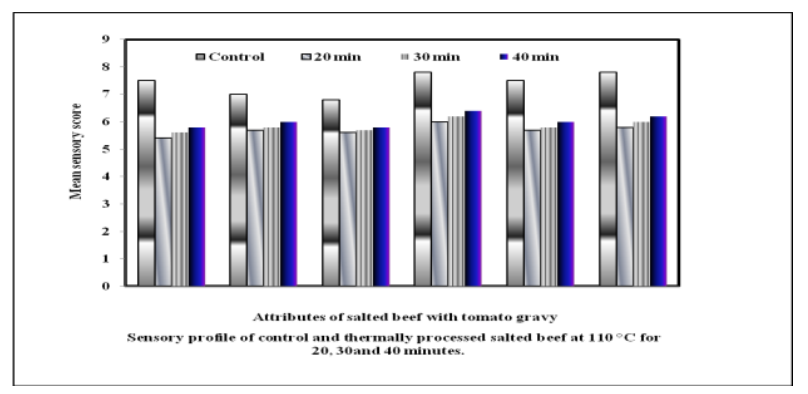




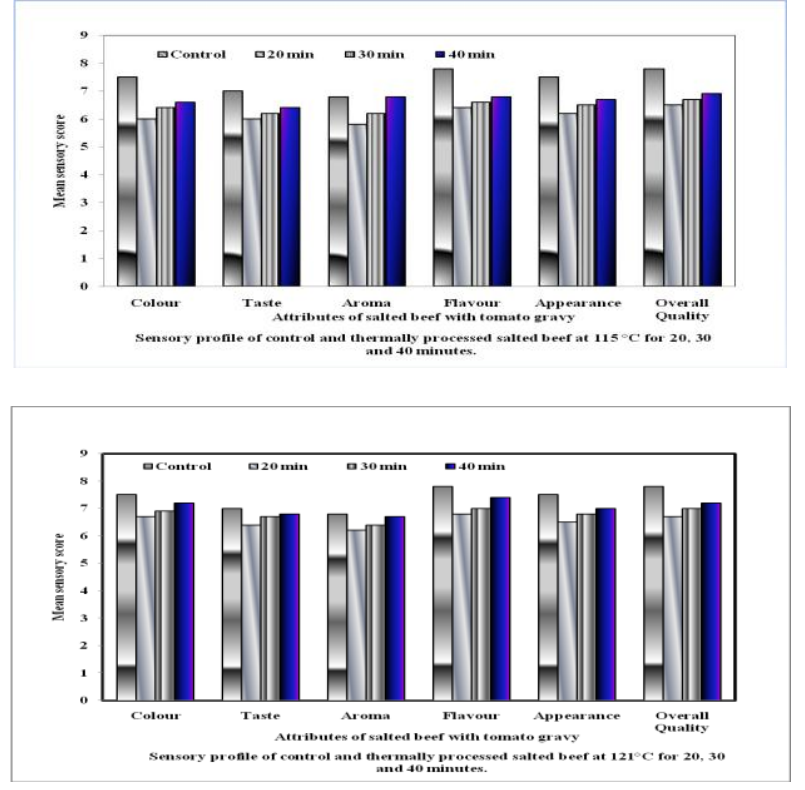

IV. Summary And Conclusions

The results summarized and drawn after the present research entitled "effect of thermal processing on shelf stable canned salted beef with tomato gravy" are given below -

1. Beef meat chunks and tomato gravy was used for development salted meat with tomato gravy. Meat chunks considered for each can weighs, $250 \mathrm{~g}$ weight of each chunk, $25 \mathrm{~g}$.

2. The product standardization of salted beef with tomato gravy was done by using finishing technique, by maintaining the filling temperature, at $80^{\circ} \mathrm{C}$ and by maintaining head space $(1.10 \mathrm{~cm})$ of the salted beef with tomato gravy. Curd was used as an emulsifier to maintain the consistency of the gravy.

3. The product standardization of salted beef with tomato gravy was done by maintaining the consistency of the tomato gravy depends on the weight with all essential ingredients for each can, 250g. Proper filling resists the breaking of emulsion. Proper emulsification was achieved by using curd (50ml for each can) as an emulsifier.

4. Microbiological analysis was carried out to depict the shelf stability of canned Salted Beef with Tomato Gravy and was carried out after every 15-day time interval up to 60 days. It was observed by the statistical analysis of microbial count that the canned meat at $121^{\circ} \mathrm{C}$ for 40 min having mean values at temperature TE3, i.e., 15.67, at time T3, i.e., 14.00 and the interaction at $\mathrm{TE} 3+\mathrm{T} 3$, i.e., 4.00 were significantly superior to other samples.

5. Similarly the chemical analysis was done. After the chemical analysis it was observed in the protein, fat, $\mathrm{pH}$ and moisture content percentage at $110^{\circ} \mathrm{C}$ for $40 \mathrm{~min}$ had the significant mean values at temperature TE1, i.e., 17.51, at time $\mathrm{T} 1$, i.e., 17.64 and the interaction at $\mathrm{TE} 1+\mathrm{T} 1$, i.e., 17.85 was significantly superior than other samples.

6. Thermal processing was done at three different temperature time combinations. From the mean sensory score it was predicted that canned meat which was thermally processed at $121^{\circ} \mathrm{C}$ for 40 minutes had significantly the superior acceptability.

\subsection{Conclusion}

The present study also revealed that application of thermal treatments, emulsifier, proper filling technique and the microbial stability as well as the sensory, and the nutritive characteristics of the canned Salted Beef with Tomato Gravy were retained. Salted Beef with Tomato Gravy which was thermally processed at $121^{\circ} \mathrm{C}$ for 40 minutes had significantly superior acceptability and the adequate protein, fat, moisture content was found significantly superior in $110^{\circ} \mathrm{C}$ for $40 \mathrm{~min}$. Similarly the maximum decline in the microbial load was depicted after the canned Salted Beef with Tomato Gravy was thermally processed at $121^{\circ} \mathrm{C}$ for 40 minutes.

\section{References}

[1] Association of Official Analytical chemists, 1975 Official methods of analysis, Washington

[2] Bender, AK. and Zia, M. 1976 Meat quality and protein quality. 1. Fd. Technol. 11. 495498

[3] Charles, D. D., and Johnson, E. R., 1972, Carcass composition of the water buffalo (Bubalus bubalis). Australian Journal of Agriculture Research 23:905-911.

[4] Das, Himanish and K., Radhakrishna, 2001, Preservation of mutton as ready-to-eat curry by hurdle technology, defence food research laboratory, Siddarthanagar, Mysore, India.

[5] El-Koussy, H. A., Afifi, Y. A., Dessouki, T. A., and El-Ashry, M. A. 1977, Some chemical and physical changes of buffalo meat after slaughter. Agriculture Research Review 55:1-7. 
[6] Han. Jun, Ma and Ledward, D. A. 2004, High pressure/thermal treatment effects on the beef muscle, Meat Science 68 (3): $347-$ 355

[7] Howker, John J. ; Shults, Gary W. Wierbicki, Eugen, 1976, Effect of Combined Irradiation and Thermal Processing on Canned Beef. Army Natick Research And Development Command Mass Food Engineering Lab, . Agriculture Research Review 30 (1): 44-48

[8] Madhwaraj, M. S., S. B. Kadkol, Nair, P. R., Dhanraj, S., Govindarajan, V. S., Baliga, B. R., 1979, Central Food Technological Research Institute, Mysore, India, manuscript.

[9] Mann, J. E. and Brashears, M. M. 2004, Contribution of Humidity to the Lethality of Surface-Attached Heat-Resistant Salmonella during the Thermal Processing of Cooked Ready-to-Eat Roast Beef, Research Note, Journal of Food Protection, 70(30):762-765

[10] Morgan, A. F., Andg. E. Kern. 1934, The effect of heat upon the biological value of meat protein. J. Nutrition, $7: 367$.

[11] Pflugg, J., Esselen, W. B., 1963 in food processing operations, the AVI publishing co., $\quad$ Inc. 410.

[12] Rastogi, R., Youssef, F. G., and Gonzalez, F. D. 1978, Beef type water buffalo of Trinidad-Beefalypso. World Review of Animal Production 14(2):49 -56.

[13] Reiser, R. and Shorland, F.B. (1990), Meat Fats and Fatty Acids, journal of food science and technology, (2)5: 21 -62 